\title{
ARTICLE OPEN Siderite micro-modification for enhanced corrosion protection
}

\author{
Wassim Taleb ${ }^{1}$, Frederick Pessu ${ }^{1}$, Chun Wang ${ }^{1}$, Thibaut Charpentier ${ }^{1}{ }^{1}$, Richard Barker ${ }^{1}$ and Anne Neville ${ }^{1}$
}

Production of oil and gas results in the creation of carbon dioxide $\left(\mathrm{CO}_{2}\right)$ which when wet is extremely corrosive owing to the speciation of carbonic acid. Severe production losses and safety incidents occur when carbon steel (CS) is used as a pipeline material if corrosion is not properly managed. Currently corrosion inhibitor $(\mathrm{Cl})$ chemicals are used to ensure that the material degradation rates are properly controlled; this imposes operational constraints, costs of deployment and environmental issues. In specific conditions, a naturally growing corrosion product known as siderite or iron carbonate $\left(\mathrm{FeCO}_{3}\right)$ precipitates onto the internal pipe wall providing protection from electrochemical degradation. Many parameters influence the thermodynamics of $\mathrm{FeCO}_{3}$ precipitation which is generally favoured at high values of temperatures, pressure and $\mathrm{pH}$. In this paper, a new approach for corrosion management is presented; micro-modifying the corrosion product. This novel mitigation approach relies on enhancing the crystallisation of $\mathrm{FeCO}_{3}$ and improving its density, protectiveness and mechanical properties. The addition of a silicon-rich nanofiller is shown to augment the growth of $\mathrm{FeCO}_{3}$ at lower $\mathrm{pH}$ and temperature without affecting the bulk $\mathrm{pH}$. The hybrid $\mathrm{FeCO}$ exhibits superior general and localised corrosion properties. The findings herein indicate that it is possible to locally alter the environment in the vicinity of the corroding steel in order to grow a dense and therefore protective $\mathrm{FeCO}_{3}$ film via the incorporation of hybrid organic-inorganic silsesquioxane moieties. The durability and mechanical integrity of the film is also significantly improved.

npj Materials Degradation (2017)1:13; doi:10.1038/s41529-017-0014-1

\section{INTRODUCTION}

While energy demands keep rising, hydrocarbons are set to remain the core power source for the next 50 years although renewable alternatives and nuclear options evolve but are not sufficient to close the gap. ${ }^{1}$ Depending on the major gas present in the system, both production and transmission steel pipelines can be subjected to sweet $\left(\mathrm{CO}_{2}\right)$ and sour $\left(\mathrm{H}_{2} \mathrm{~S}\right)$ corrosion. ${ }^{2}$ In the upstream oil and gas operations, $\mathrm{CO}_{2}$ corrosion is shown to be responsible for the major degradation mechanisms and accounts for $>25 \%$ of safety incidents. ${ }^{3}$ There is a current network of thousand kilometres of pipelines and transportation infrastructure across the UK and US and for these to operate efficiently, corrosion should be managed in an optimum way. The current primary mode of managing corrosion in oil and gas is the deployment of chemicals in batch or continuous treatments for a typical well and these imply not only huge operational expenditure but are also often harmful to the environment. As such, being able to reduce chemical deployment and engineer the corrosion product would present a paradigm shift in corrosion management.

Many environmental, physical and metallurgical influencing factors act interdependently to affect the formation of a protective $\mathrm{FeCO}_{3}$ corrosion layer. ${ }^{4-7} \mathrm{FeCO}_{3}$ can develop as an amorphous or crystalline structure; in the latter case, it forms as a crystalline system which is identical to calcite scale ${ }^{8}$ especially when both $\mathrm{pH}$ and temperatures are high. ${ }^{9-11} \mathrm{FeCO}_{3}$ can reduce the corrosion rate (CR) to values that are 10 times lower, ${ }^{12}$ when compared to the $\mathrm{CR}$ achieved when common $\mathrm{Cl}$ are administered (Supplementary Table S1) but thus far, there has been no attempt to chemically modify its structure or adapt its density in-situ.
When the $\mathrm{FeCO}_{3}$ film is partially removed, localised corrosion can initiate and such a scenario can be detrimental to the life expectancy of the transport installations. ${ }^{13}$ Its stability can be breached by turbulent flow, ${ }^{14}$ erosive wear ${ }^{15}$ and pH instability. ${ }^{16-18}$ Attempts have been made to increase the formation of $\mathrm{FeCO}_{3}$ by the $\mathrm{pH}$ stabilisation technique, however this approach presents an inherent drawback that the bulk $\mathrm{pH}$ is modified, thus enhancing other flow assurance issues, mainly calcium carbonates $\left(\mathrm{CaCO}_{3}\right)$ and barium sulphates $\left(\mathrm{BaSO}_{4}\right)$ scaling. ${ }^{19,20}$

Advances in biomineralisation research shows how many organisms are known to drastically enhance the toughness of brittle ceramics, like calcium carbonate by adding just a few weight percentage of organic macromolecules. ${ }^{21}$ To this regard, inhomogeneous distributions of $\mathrm{nm}$-sized organic inclusions have been shown by small-angle X-ray scattering in individual calcitic crystallites extracted from specific mollusk shells thus creating an organic-inorganic material with enhanced mechanical properties. ${ }^{22}$ To accommodate an inorganic matrix such as $\mathrm{FeCO}_{3}$, which is the iron counterpart of calcite, a hybrid nanofiller could be used. Recently, focus on polyhedral oligomeric silsesquioxane (POSS) molecules as hybrid nanofiller (Supplementary Fig. S1) have increased since they have proven to successfully incorporate various matrices. ${ }^{23}$ The empirical formula of silsesquioxane is $\left(\mathrm{RSiO}_{1.5}\right)_{2 n}$ where $n$ is an integer and $\mathrm{R}$ is an organic compound. The inorganic part is $\mathrm{Si}_{8} \mathrm{O}_{12}$ if $n=4$ and it usually provides hardness and strength thus accounting for the molecular reinforcement due to the rigid $\mathrm{Si}-\mathrm{O}$ bonds while the organic chains $(-R)$ can span a whole range of chemistries in order to better adapt to the polymer and safe keep its elasticity, plasticity and rubbery (Supplementary Fig. S1)..$^{24}$

The new approach described in this paper focuses on growing $\mathrm{FeCO}_{3}$ in $\mathrm{CO}_{2}$ corrosion conditions at lower $\mathrm{pH}$ and temperature

${ }^{1}$ Institute of Functional Surfaces, School of Mechanical Engineering, University of Leeds, Woodhouse Lane, Leeds LS2 9JT, UK

Correspondence: Wassim Taleb (w.taleb@leeds.ac.uk)

Received: 4 April 2017 Revised: 20 June 2017 Accepted: 10 July 2017

Published online: 16 October 2017 
while maintaining a stable bulk $\mathrm{pH}$. It relies on a solvent blending technique of a specific commercially available POSS molecule with the $\mathrm{FeCO}_{3}$ film in order to obtain a hybrid corrosion film. This is the first known attempt to modify a corrosion product by in-situ reaction of an organic-inorganic hybrid material; it shows that $\mathrm{FeCO}_{3}$ crystals can nucleate at lower temperature and bulk pH values than previously assumed. The work also describes the mechanical and electrochemical properties and the densification of the $\mathrm{FeCO}_{3}$ film; mainly its higher localised corrosion mitigation and hardness and Young's modulus enhancement are characterised.

\section{RESULTS}

General corrosion rate evolution

When the temperature is equal of $60^{\circ} \mathrm{C}$ or below, it is difficult to form a fully protective crystalline $\mathrm{FeCO}_{3}$ corrosion film (Supplementary Fig. S2). ${ }^{25}$ This observation is confirmed with the experiments ran at a $\mathrm{pH}$ of 6.6 and a $3.5 \% \mathrm{NaCl}$ saturated with $\mathrm{CO}_{2}$ as per Fig. $1 \mathrm{a}$, where the evolution of the $\mathrm{CR}$ in a blank test for the first $40 \mathrm{~h}$ fluctuates around 3 millimetres per year $(\mathrm{mm} / \mathrm{yr})$. This stable corrosion behaviour is correlated with the absence of an $\mathrm{FeCO}_{3}$ protective film (Figs. $2 \mathrm{a}$ and $3 a$ ). The formation of $\mathrm{FeCO}_{3}$ at the surface of steel is a heterogeneous surface crystallisation
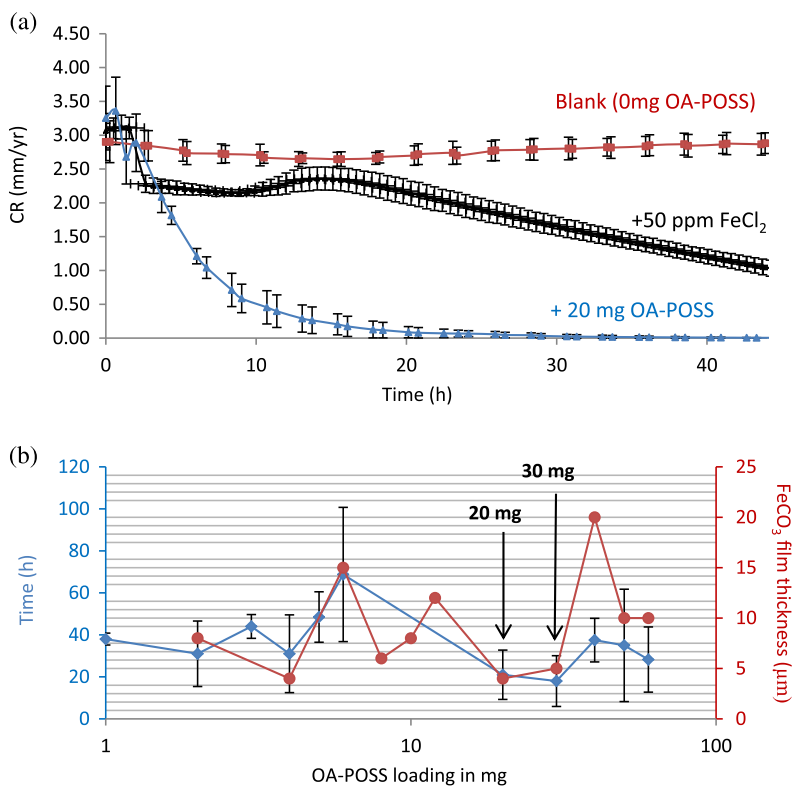

Fig. $1 \mathrm{CR}$ variation in $\mathrm{mm} / \mathrm{yr}$ vs. time in hours for a blank, $\mathrm{FeCl}_{2}$ enriched and OA-POSS enriched medium a and the time to reach $0.3 \mathrm{mmpy}$ for different OA-POSS loadings in hours compared to the respective cross-section $\mathrm{FeCO}_{3}$ film thicknesses in microns $\mathbf{b}$ at a $\mathrm{pH}$ of 6.6 and at $60^{\circ} \mathrm{C}$ in a $3.5 \% \mathrm{NaCl}$ in a $\mathrm{CO}_{2}$ saturated brine

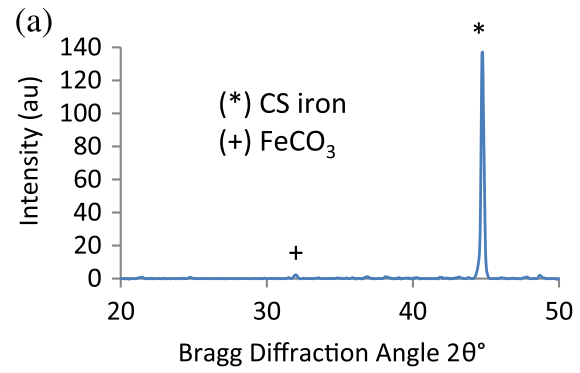

process; it is controlled by the high concentration of ferrous ions produced when the steel corrodes. The local chemistry at the interface is dictated by the environmental conditions and directly affects the growth kinetics of the $\mathrm{FeCO}_{3}$ crystals. At the chosen conditions $\left(60^{\circ} \mathrm{C}, \mathrm{pH}=6.6, \mathrm{CO}_{2}\right.$ pressure $=0.8$ bar, ionic strength $=$ $0.82 \mathrm{Mol}$ ), the solution is undersaturated with an $\mathrm{FeCO}_{3}$ bulk saturation ratio equal to 0.619 if computed as per Nordsveen et al. ${ }^{26}$ and assuming that all the ferrous iron ions produced from the general corrosion process are dissolved in the bulk solution.

The addition of ferrous chloride $\left(\mathrm{FeCl}_{2}\right)$ is known to provide the required ferrous ions $\left(\mathrm{Fe}^{2+}\right)$ needed to reach the $\mathrm{FeCO}_{3}$ supersaturation faster and thus facilitates the crystallisation of $\mathrm{FeCO}_{3}$. Nonetheless, the registered $C R$ drop remains much slower if compared to tests where octa-ammonium POSS (OA-POSS) is added (Fig. 1a) and this is explained by the $\mathrm{FeCO}_{3}$ protective film growth (Figs. 2b and $3 \mathrm{~b}$ ).

It should be noted that the CR only drops when the OA-POSS is administered after a pre-corrosion time of $2 \mathrm{~h}$; otherwise the $C R$ values remain stable over $98 \mathrm{~h}$ even when OA-POSS is dissolved at the start (Supplementary Figs. S3 and S4). The CR reached values below $0.1 \mathrm{~mm} / \mathrm{yr}$ in $<20 \mathrm{~h}$ (Fig. 1a) and this fast kinetic effect was followed up more closely by running a synchrotron in-situ X-ray diffraction (XRD) test which showed that the first $\mathrm{FeCO}_{3}$ peaks appeared after $3.5 \mathrm{~h}$ as per Supplementary Fig. S5. As expected when a protective $\mathrm{FeCO}_{3}$ film is present and fully developed, the CR stabilises at values lower than $0.01 \mathrm{~mm} / \mathrm{yr}$.

The corrosion kinetics and $\mathrm{FeCO}_{3}$ film growth vary with the $\mathrm{OA}$ POSS concentration and it was observed that at 20 and $30 \mathrm{mg} \mathrm{OA-}$ POSS offer the best protection (Fig. 1b). The corresponding CR drop overlaps with the thinnest $\mathrm{FeCO}_{3}$ corrosion layers ranging between 4 and $5 \mu \mathrm{m}$ (Fig. 1b). The micrographs depicting the cross-sections from which the average $\mathrm{FeCO}_{3}$ film thicknesses were estimated are shown in Supplementary Fig. S6. A full description of the CR behaviour at OA-POSS loadings ranging from as low as $1 \mathrm{mg}$ to as high as $100 \mathrm{mg}$ are depicted in Supplementary Fig. S7, where the OA-POSS is shown to be potent even at the lowest concentrations which are comparable to common $\mathrm{Cl}$ dosage.

The drop in the CR previously described can be directly linked to the OA-POSS molecules playing the role of $\mathrm{FeCO}_{3}$-nucleating agents allowing the $\mathrm{FeCO}_{3}$ to densify and consolidate much quicker than in the absence of OA-POSS. Such effect has been referenced before, when the POSS has been described to act as a weak-crosslinker by helping increase the crystallisation rate of POSS/polysiloxane elastomer composites. ${ }^{27}$ Surface analysis using techniques such as XRD (Supplementary Fig. S8) and scanning electron microscopy (SEM) (Supplementary Figs. S9 and S10) validate the establishment of the $\mathrm{FeCO}_{3}$ crystalline corrosion film for all the range of OA-POSS concentrations tested. Moreover, regardless of the degree of protection, there appears to be a denser $\mathrm{FeCO}_{3}$ layer when the OA-POSS loading is increased (Supplementary Fig. S11).

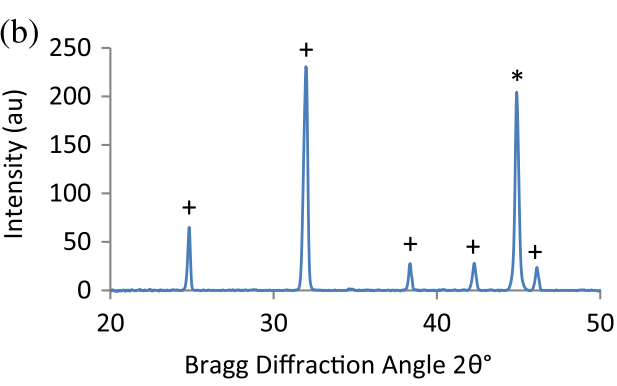

Fig. 2 XRD pattern for blank $\mathbf{a}$ and OA-POSS $(20 \mathrm{mg})$ enriched $\mathrm{FeCO}_{3}$ film $\mathbf{b}$ The $\left.{ }^{*}\right)$ depicts the peaks corresponding to the iron atom present in the CS studied samples while the $(+)$ sign shows where the $\mathrm{FeCO}_{3}$ peaks or diffraction angles are with accordance to the FeCO crystallographic parameters where the major [104] Miller index for $\mathrm{FeCO}_{3}$ coincides with the $32^{\circ}$ Bragg diffraction angle 
(a)

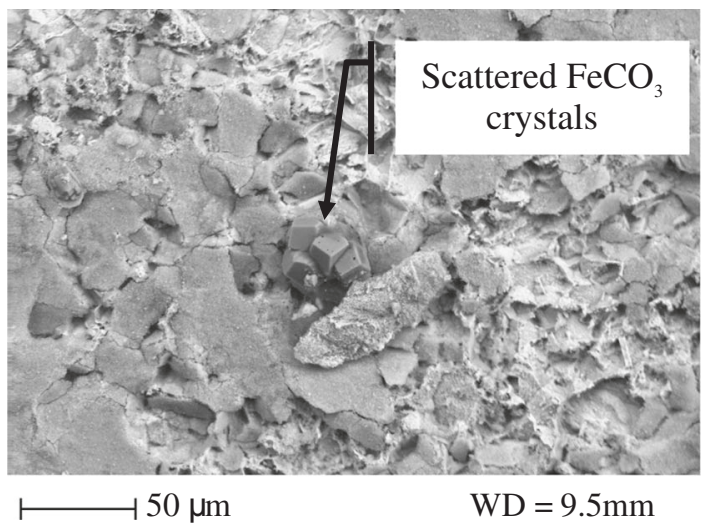

(b)

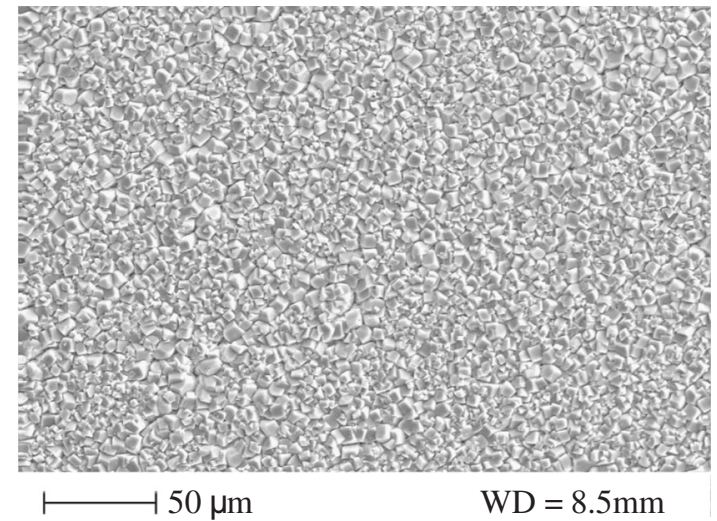

Fig. 3 SEM micrographs of a blank test when no OA-POSS is administered showing isolated $\mathrm{FeCO}_{3}$ crystals a and OA-POSS (20 mg) modified

$\mathrm{FeCO}_{3}$ compact layer $\mathbf{b}\left(\mathrm{pH}=6.6,60^{\circ} \mathrm{C}, 3.5 \% \mathrm{NaCl}, 98 \mathrm{~h}\right)$
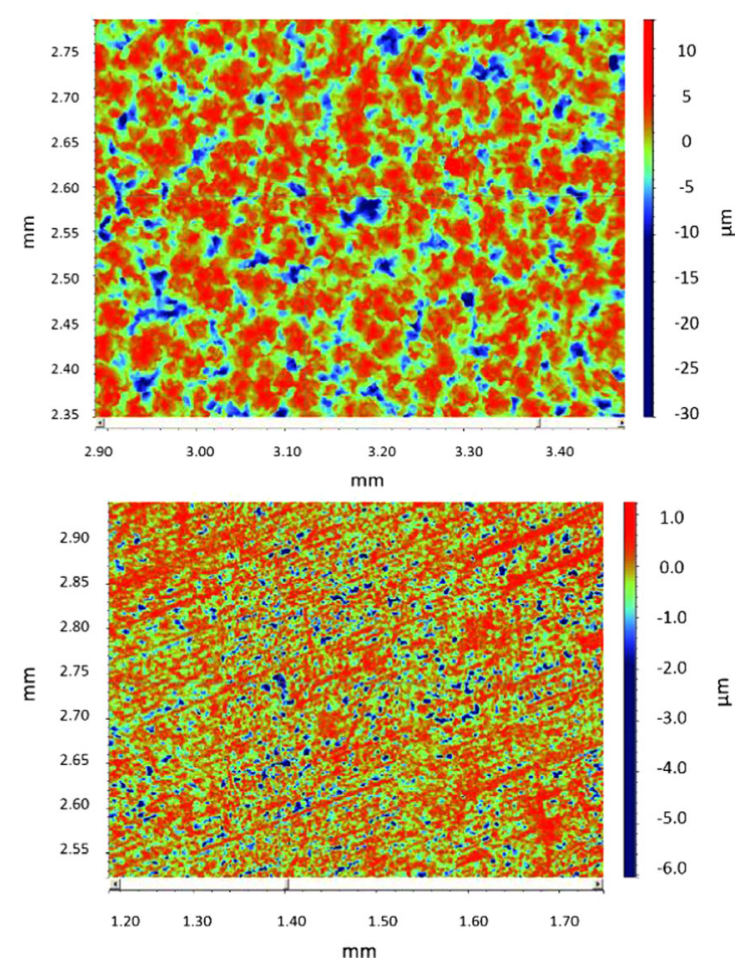

(a)

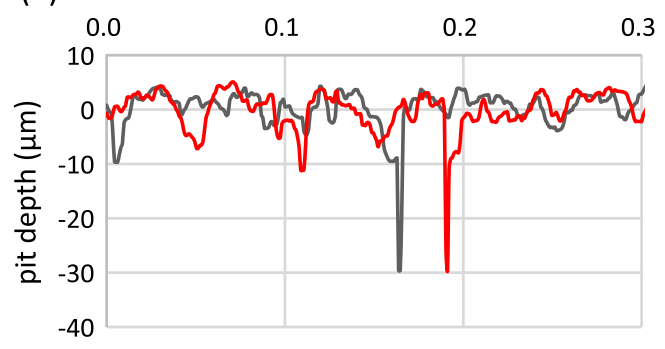

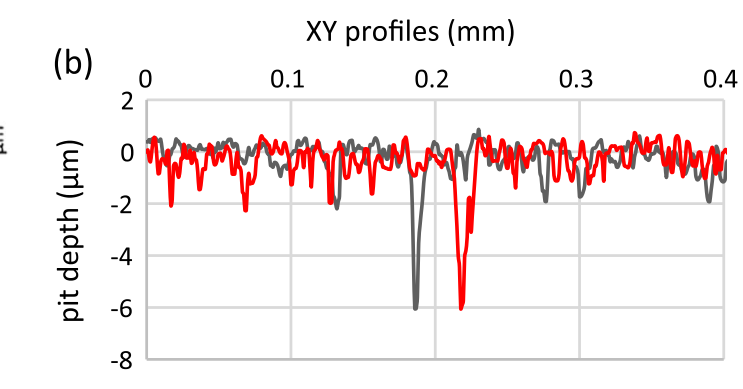

Fig. 4 Vertical light interferometry 2D images of the deepest pits obtained for the surface beneath an $\mathrm{FeCl}_{2} \mathrm{grown} \mathrm{FeCO}_{3}$ film a and a 30 mg $\mathrm{OA}-\mathrm{POSS}$ enriched $\mathrm{FeCO}_{3}$ layer $\mathbf{b}$ The left side correspond to the horizontal profile with the sample dimensions in mm and the topographic height variation in micrometres. The right side corresponds to the coordinates of a designated deepest pit. Analysis was carried out on samples after being subjected to the corrosive environment for $98 \mathrm{~h}$

\section{Localised corrosion effect}

Optical interferometry was used in order to assess the effect of OA-POSS addition on the pit distribution once the $\mathrm{FeCO}_{3}$ layer is removed. As a reference, $\mathrm{FeCO}_{3}$ film formed in the absence of OAPOSS was obtained via the addition of $\mathrm{FeCl}_{2}(50 \mathrm{ppm})$. As such, Fig. 4a shows that the pits which grew under a naturally growing $\mathrm{FeCO}_{3}$ layer are around $30 \mu \mathrm{m}$ deep. On the other hand, $\mathrm{FeCO}_{3}$ corrosion films grown in the presence of $30 \mathrm{mg}$ OA-POSS appear to be more protective with regard to localised corrosion since the deepest pits are found to be around $6 \mu \mathrm{m}$ (Fig. 4b). If $20 \mathrm{mg} \mathrm{OA}$ POSS is added, both the pit depth and pit count dropped drastically (Fig. 5a). The tendency for localised corrosion to initiate and propagate is something that is extremely important for the lifetime of CS pipelines so the apparent reduction of localised corrosion afforded by the OA-POSS-derived $\mathrm{FeCO}_{3}$ film could be very useful in mitigating CS localised corrosion phenomena. Vertical light interferometry 3D schemes are shown in Supplementary Fig. S12 and these depict two distinct morphologies when the surface beneath both naturally growing and OA-POSSaltered $\mathrm{FeCO}_{3}$ films are compared. One explanation of the pit count drop could be linked to a much thinner $\mathrm{FeCO}_{3}$ layer and containing smaller crystals which are known to provide better protection.

Hardness and Young's modulus enhancement

The nanoindentation technique was used to compute the hardness and Young's modulus of the studied $\mathrm{FeCO}_{3}$ films. The 
(a) 35

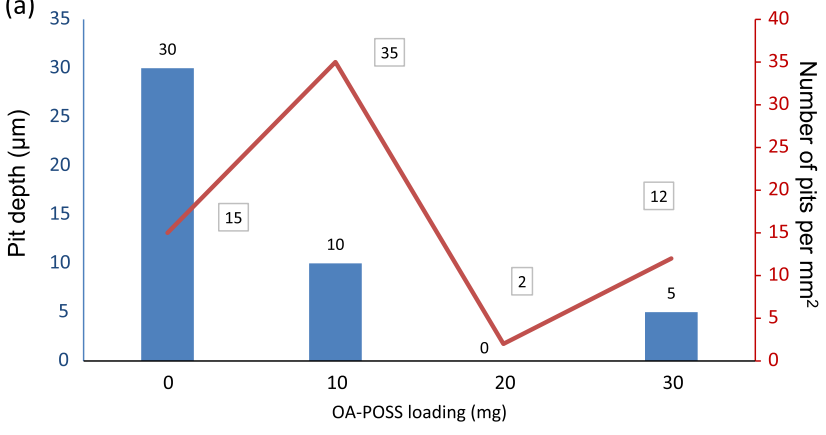

Pit depth in micrometers _Pit counts per square millimeters

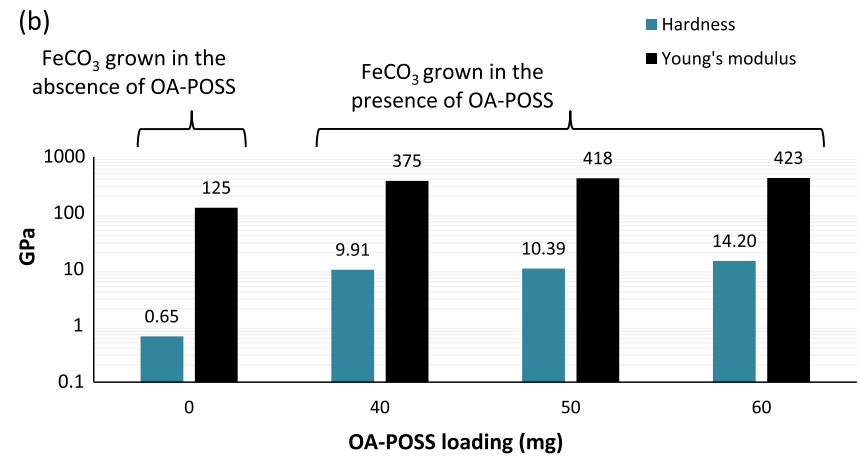

Fig. 5 Maximum pit depths and pit count at various OA-POSS concentrations a Mechanical properties obtained from ferrous enriched $\left(50 \mathrm{ppm} \mathrm{FeCl}_{2}\right.$ and $0 \mathrm{mg} \mathrm{OA-POSS}$ ) and b OA-POSS enriched $\left(40,50\right.$ and $60 \mathrm{mg}$ OA-POSS) $\mathrm{FeCO}_{3}$ corrosion layers $(\mathrm{pH}$ $\left.=6.6,60^{\circ} \mathrm{C}, 3.5 \% \mathrm{NaCl}, 108 \mathrm{~h}\right)$

$\mathrm{FeCO}_{3}$ layer with $0 \mathrm{mg}$ OA-POSS was grown using $50 \mathrm{mg}$ of $\mathrm{FeCl}_{2}$. It appears from Fig. $5 \mathrm{~b}$ that the hardness is increased 10 -fold from values, as low as $700 \mathrm{MPa}$ to values as high as $14 \mathrm{GPa}$. On the other hand, the Young's modulus of these films is also augmented by a factor of 4 from values ranging between 100 and $400 \mathrm{GPa}$ and these are comparable to previously published data. ${ }^{28} \mathrm{~A}$ higher Young's modulus is usually obtained after a reduction in the material's porosity and indicates higher mechanical flexibility. This mechanical enhancement of the OA-POSS $\mathrm{FeCO}_{3}$ modified corrosion films can be attributed to the $\mathrm{Si}$ uptake from the silsesquioxane cage structure as shown from the inductively coupled plasma optical emission (ICP-OES) results. In fact the $\mathrm{Si}$ content in the hybrid $\mathrm{FeCO}_{3}$ films varies between 1.5 and $2 \mathrm{ppm}$ regardless of the OA-POSS concentration while the Si content in the naturally growing $\mathrm{FeCO}_{3}$ film is as low as $0.2 \mathrm{ppm}$ (Fig. 6a).

The loading-unloading curves show that the depths values are scattered between 200 and $2500 \mu \mathrm{m}$, when the indentation is carried out on an $\mathrm{FeCO}_{3}$ film which was grown in the presence of 50 ppm $\mathrm{FeCl}_{2}$, while these are condensed between 20 and $200 \mu \mathrm{m}$ in the case of the OA-POSS modified $\mathrm{FeCO}_{3}$ (Supplementary Fig. S13). The hardness and Young's modulus values observed in Fig. $5 \mathrm{~b}$ are of interest since the hardness of the $\mathrm{FeCO}_{3}$ grown in the absence of OA-POSS $(0.65 \mathrm{GPa})$ is comparable to published mechanical properties of general corrosion products. Moreover, the enhancement introduced by the POSS addition is also in the same order of magnitude when various POSS entities are blended to commonly researched polymers, that is 3-10 times higher hardness and Young's modulus values. ${ }^{29,} 30$

Increasing the hardness of the $\mathrm{FeCO}_{3}$ film is important since it provides the required durability and the ability to resist environmental stresses such as erosive wear. ${ }^{31}$ Having a higher ERP at medium OA-POSS loadings, the hybrid $\mathrm{FeCO}_{3}$ is expected to be more rubbery and able to withstand various flow effects (Fig. 6b).
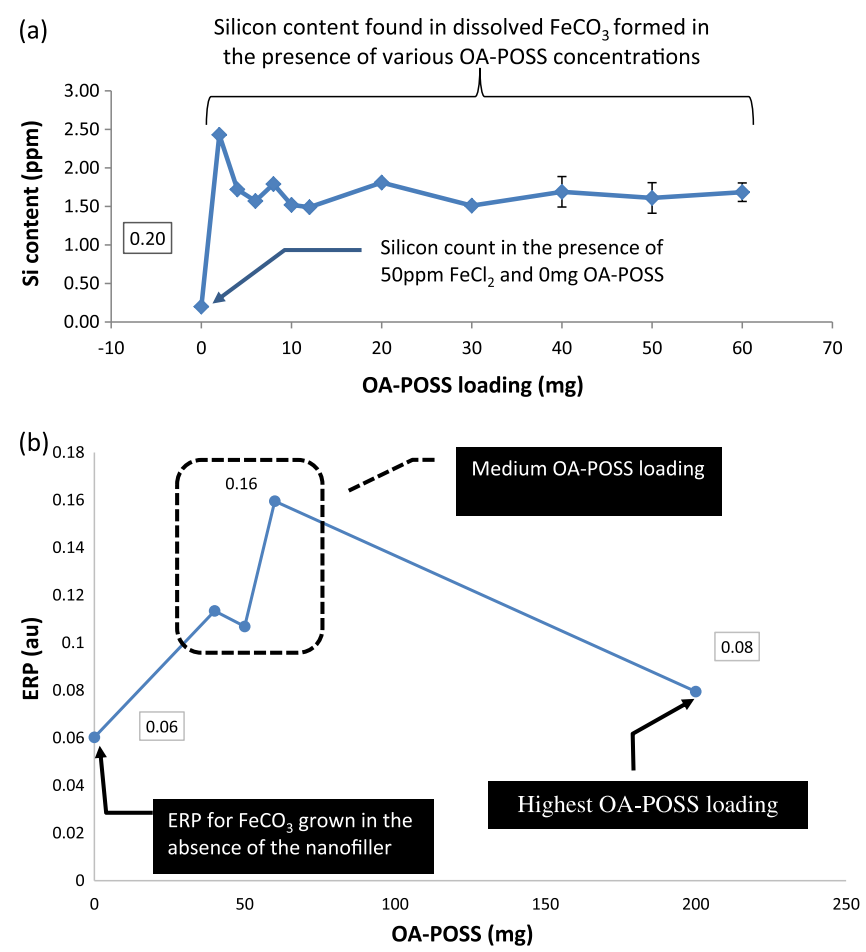

Fig. 6 Silicon uptake as computed from the ICP-OES analysis a and ERP at different OA-POSS concentrations showing that the highest values correspond to medium concentrations of the nanofiller $\mathbf{b}$

\section{DISCUSSION}

The work proposed herein focused on building an inorganic/ organic/inorganic composite of $\mathrm{FeCO}_{3}$ in-situ with silsesquioxane based nanoscale filler species. As the nanofiller is seen to provide better electrochemical results after a pre-corrosion period, it is assumed that the increased surface roughness will help the OAPOSS adsorb onto the carbon steel exposed surface as evidenced by the growth of the inductive loops as per the electrochemical impedance spectroscopy (EIS) data (Supplementary Fig. 2b). Once the hybrid nanofiller is available at the steel surface, it is postulated that it interacts with the $\mathrm{FeCO}_{3}$ precursor, reducing the activation energy which is necessary for the crystal nucleation process to occur. Consequently, once the first set of $\mathrm{FeCO}_{3}$ nuclei start showing, an interlacing hybrid $\mathrm{FeCO}_{3}$ which is rich with $\mathrm{OA}$ POSS on the CS side (Supplementary Fig. S14g) develops and provides a higher general and localised corrosion protection.

A detailed description of the assumed sequence of events is shown in Supplementary Fig. S15. The positively charged ammonium groups on the OA-POSS side-chains adsorb to the negatively charged pearlite areas before being solvated with chlorides and working as sinks for the ferrous iron produced from the corrosion mechanism and thus raising locally its concentration and bringing the supersaturation value closure to the threshold which permit the first $\mathrm{FeCO}_{3}$ crystals to start forming.

The present work shows that at specific conditions of $\mathrm{pH}$ and temperature where $\mathrm{FeCO}_{3}$ films are known not to naturally evolve without further ferrous iron additions, OA-POSS which a hybrid organic-inorganic nanofiller accelerates the kinetics of formation and enhances the mechanical properties of the $\mathrm{FeCO}_{3}$ corrosion layer. Furthermore, processes and effects have been characterised and the $\mathrm{FeCO}_{3}$ films which develop in the presence of OA-POSS display better hardness and modulus properties, when compared with the naturally occurring corrosion layers while safekeeping their ERP values. The OA-POSS can actually assist in $\mathrm{FeCO}_{3}$ crystals nucleation at a $\mathrm{pH}$ as low as 5 (Supplementary Fig. S16); these results are very promising and it could be hoped that altering the 
nanofiller side-chains in a way that will help resist the acidic environmental hydrolysis of the siloxane $\mathrm{Si}-\mathrm{O}-\mathrm{Si}$ could prove very beneficial in order to grow $\mathrm{FeCO}_{3}$ protective films at even lower $\mathrm{pH}$ values than the ones tested in this research.

\section{METHODS}

Nanofiller selection strategy

The nanofiller of choice was OA-POSS with the chemical formula $\mathrm{C}_{24} \mathrm{H}_{72} \mathrm{Cl}_{8} \mathrm{~N}_{8} \mathrm{O}_{12} \mathrm{Si}_{8}$ and a molecular weight of $1173.18 \mathrm{~g} / \mathrm{mol}$ (Supplementary Information Fig. S1); OA-POSS is biocompatible ${ }^{32}$ and being water soluble, it could be administered in the water phase as any industrial corrosion inhibitor $(\mathrm{Cl})$ since most transport systems are oil in water phases. OA-POSS is also positively charged due to the eight ammoniums side chains $-\mathrm{R}$ where $-\mathrm{R}$ is $-\mathrm{CH}_{2}-\mathrm{CH}_{2}-\mathrm{CH}_{2}-\mathrm{NH}_{3}{ }^{+} \mathrm{Cl}^{-}$, which enhances the electrostatic attraction with the negatively charged zeta potential ${ }^{33}$ of the $\mathrm{FeCO}_{3}$ or carbon steel at the chosen $\mathrm{pH}$. The nitrogen groups in the ammonium moiety are known to be good etchants in a similar way to the nitrogen groups recurrently used in any generic $\mathrm{CO}_{2} \mathrm{Cl}$ and the Si-group from the OA-POSS molecule core is known to have good sorption on many corrosion products. ${ }^{34}$ The nanofiller was dissolved at different loadings in $\mathrm{CO}_{2}$ saturated distilled water at $60^{\circ} \mathrm{C}$ before being added with a pipette after the CS X65 samples have been subjected to $2 \mathrm{~h}$ of pre-corrosion. The OA-POSS weight to be added was computed as if 3-5\% by weight of the $\left(\mathrm{FeCO}_{3}+\mathrm{OA}-\mathrm{POSS}\right)$ blend should be added to incorporate in a $50 \mu \mathrm{m}$ thick $\mathrm{FeCO}_{3}$ film since POSS moieties appears to be most efficient in these ranges. $^{30,35,36}$ Moreover, lower loadings similar to the ones used in $\mathrm{Cl}$ administration in the order of the ppm were also tested.

\section{Electrochemical tests}

Bubble tests ${ }^{37}$ were run in static conditions and at atmospheric pressure with and without OA-POSS in order to assess the nanofiller effect on CR variation and to follow the topography of the corrosion film evolution. The brine with a $3.5 \% \mathrm{NaCl}$ salinity had a volume of one litre, and the desired $\mathrm{pH}$ of 6.6 was buffered at the start via addition of anhydrous $\mathrm{NaHCO}_{3}$ then monitored periodically thereafter and found to be stable for the experiment duration. The brine was saturated with $\mathrm{CO}_{2}$ which was bubbled continuously at 0.54 bar until the end of the test. The material of choice serving as the working electrode in the electrochemical three electrode test setup was API-5L- X65 (Supplementary Fig. S17 and Table S2). These were $15 \times 15 \times 5 \mathrm{~mm}$ squared samples that have been wet-ground in sequence of 120, 320 and 600 grit emery papers, degreased in acetone and rinsed with ethanol after being cast in resin. It should be noted that free drift experiments were ran by dropping the $\mathrm{pH}$ gradually from a value of seven until the highest temperature $\left(60^{\circ} \mathrm{C}\right)$ and $\mathrm{pH}(6.6)$ at which no $\mathrm{CR}$ drop was observed.

Electrochemical direct current (DC) and alternate current (AC) tests were carried out using an ACM Gill 12 potentiostat with a cell settle times of 5 min allowing for the OCP to stabilise between recurrent measurements. Tafel constants at the test start of blank and OA-POSS rich environments were computed by sweeping $\pm 300 \mathrm{mV}$ from OCP at a scan rate of $10 \mathrm{mV} /$ $\mathrm{min}$ and these were equal to 20.27 and 24.92 respectively (Supplementary Information Fig. S12). Linear polarisation resistances used to extract general corrosion rates were set up as LPR sweeps between $\pm 15 \mathrm{mV}$ from OCP at a sweep rate of $10 \mathrm{mV} / \mathrm{min}$. Electrochemical impedance spectroscopy (EIS) tests were set at an excitation voltage of $10 \mathrm{mV}$ scanning a frequency range comprised between $10 \mathrm{MHz}$ and $4 \mathrm{mHz}$.

\section{Surface analysis of corrosion products}

$X$-ray diffraction measurements were performed on a panalytical X'pert multipurpose diffractometers with a voltage of $40 \mathrm{kV}$ and an intensity of $40 \mathrm{~mA}$ using dual copper $\mathrm{Cu} \mathrm{K}_{\mathrm{a} 1+2}$ radiations with $10 \times 10 \mathrm{~mm}$ programmable divergence slits. The diffractograms were registered on iron carbonate films in the angular region of $2 \theta=20-50^{\circ}$ at room temperature and all scans were carried out in continuous mode. Phase identification was accomplished via the X'pert related software, Panalytical high score plus. These angle ranges were found satisfactory as four main Bragg angles representative of the $\mathrm{FeCO}_{3}$ crystals are in this range. In-situ synchrotron XRD characterisation shown in Supplementary information was carried out as described by Burkle et al. ${ }^{38}$

Scanning electron microscopy was carried out on the CS samples using a Carl Zeiss EVO MA15 to assess coverage and topography of the $\mathrm{FeCO}_{3}$ corrosion products. All micrographs were collected at an accelerating voltage of $20 \mathrm{kV}$ and at a working distance between 8 and $10 \mathrm{~mm}$.

Interferometry was used to measure the pit depths in alignment with ASTM G46-94 with an NPFLEX 3D interferometer in order to define the discrete geometry of pits on $1 \mathrm{~mm}^{2}$ of the steel surface. Pits were identified after carefully selecting the thresholds with distinct pit depths, diameters and areas being quantified. The corrosion products were removed by rubbing them with Clarke solution ${ }^{39}$ then rinsing with acetone and drying.

\section{Mechanical properties determination}

Nanoindentation tests were performed using the Nano Test (Micro Materials Limited, UK), with a Berkovich diamond indenter. For the purpose of statistics and reliability, 60 loading/unloading curves were made in each experiment to find the average results. All experiments were performed at a constant loading and unloading rate equal to $0.2 \mathrm{mN} / \mathrm{s}$ and to a maximum load of $1 \mathrm{mN}$ (controlled maximum load). The hold time at maximum load was $20 \mathrm{~s}$, and thermal drift correction was set at $60 \mathrm{~s}$ of holding period at $80 \%$ unloading. The unloading curves were used to derive the hardness and modulus values by analytical technique developed by Oliver and Pharr. ${ }^{40}$

\section{Elemental analysis}

Induced coupled plasma was used to check for the silicon content in the iron carbonate corrosion films after dissolving those in $15 \%$ acetic acid. Each sample was diluted 10 -fold in $1 \%$ nitric acid before analysis and the instrument was calibrated between 0.1 and $0.5 \mathrm{ppm} \mathrm{Si}$, while the detection limit was determined from the instrument calibration curve to be $0.2 \mathrm{ppm}$ $\mathrm{Si}$. The precision of the analysis was determined by analysing one sample ( $2 \mathrm{mg}$ OA-POSS) six times and calculating the $95 \%$ uncertainty interval while the accuracy of the analysis was determined by spiking one sample ( $2 \mathrm{mg}$ OA-POSS again) with a known amount of Si, analysing if six times and calculating the recovery.

\section{Data availability}

The data that support the findings of this study are available from the corresponding author upon reasonable request.

\section{AUTHOR CONTRIBUTIONS}

The manuscript was written through contributions of all authors. W.T. designed the experiments and performed most of the laboratory tasks. F.P. helped acquire and analyse the interferometry data. C.W. contributed with the nanoindentation data measurement. All authors have given approval to the final version of the manuscript.

\section{ADDITIONAL INFORMATION}

Supplementary Information accompanies the paper on the npj Materials Degradation website (doi:10.1038/s41529-017-0014-1).

Competing interests: The authors declare that they have no competing financial interests.

Publisher's note: Springer nature remains neutral with regard to jurisdictional claims in published maps and institutional affiliations.

\section{REFERENCES}

1. Abas, N., Kalair, A. \& Khan, N. Review of fossil fuels and future energy technologies. Futures 69, 31-49 (2015).

2. Papavinasam, S. in Corrosion Control in the Oil and Gas Industry (ed Sankara Papavinasam) Ch. 1, 1-39 (Gulf Professional Publishing, 2014)

3. Kermani, M. B. \& Morshed, A. in CORROSION. 659-683 (NACE International, 2003)

4. Waard, C., Lotz, U. \& Milliams, D. E. Predictive Model for $\mathrm{CO}_{2}$ corrosion engineering in wet natural gas pipelines. Corrosion 47, 976-985 (1991).

5. Dugstad, A. in CORROSION. 061111-0611118 (NACE International, 2006)

6. Eliyan, F. F. \& Alfantazi, A. On the theory of $\mathrm{CO}_{2}$ corrosion reactions - investigating their interrelation with the corrosion products and api-x100 steel microstructure. Corros. Sci. 85, 380-393 (2014).

7. Tanupabrungsun, T., Brown, B. \& Nesic, S. in CORROSION. (NACE International, 2013).

8. Chai, L. \& Navrotsky, A. Synthesis, characterization, and enthalpy of mixing of the $(\mathrm{Fe}, \mathrm{Mg}) \mathrm{CO}_{3}$ solid solution. Geochim. Cosmochim. Acta 60, 4377-4383 (1996). 
9. Hernandez, J., Muñoz, A. \& Genesca, J. Formation of iron-carbonate scale-layer and corrosion mechanism of APIX70 pipeline steel in carbon dioxide-saturated $3 \%$ sodium chloride. Afinidad 69, 251-258 (2012).

10. Dugstad, A. in CORROSION Paper no. 31 (NACE International, Houston, TX, 1998).

11. Ingham, B., Ko, M., Laycock, N., Kirby, N. M. \& Williams, D. E. First stages of siderite crystallisation during $\mathrm{CO}_{2}$ corrosion of steel evaluated using in situ synchrotron small- and wide-angle X-ray scattering. Faraday Discuss. 180, 171-190 (2015).

12. Sim, S., Cole, I. S., Choi, Y. S. \& Birbilis, N. A review of the protection strategies against internal corrosion for the safe transport of supercritical $\mathrm{CO} 2$ via steel pipelines for CCS purposes. Int. J. Greenh. Gas. Control 29, 185-199 (2014).

13. Ropital, F., Chauvin, Y. \& Jones, T. in Corrosion and Degradation of Metallic Materials: Understanding of the Phenomena and Applications in Petroleum and Process Industries Ch. 1, 3-8 (Editions Technip, 2010).

14. Yang, Y. et al. in CORROSION. 19p (NACE International, 2010).

15. Al-Mutahar, F. M., Roberts, K. P., Shirazi, S. A., Rybicki, E. F. \& Shadley, J. R. in NACE International Corrosion Conference Series Vol. 1, 683-701 (2012).

16. Biegler, C. \& Houchin, M. R. Siderite $\left(\mathrm{FeCO}_{3}\right)$ : its dissolution and interaction with stannic oxide in aqueous suspensions. Colloids Surf. 21, 267-278 1986).

17. Ruzic, V., Veidt, M. \& Nešić, S. Protective Iron Carbonate Films-Part 3: simultaneous chemo-mechanical removal in single-phase aqueous flow. Corrosion 63, 758-769 (2007).

18. Yang, Y., Brown, B. \& Nesic, S. in CORROSION. 16 (NACE International, 2013).

19. Kvarekval, J. \& Dugstad, A. in CORROSION. 066461-0664615 (NACE International, 2006)

20. Zheng, L., Landon, J., Matin, N. S., Thomas, G. A. \& Liu, K. Corrosion mitigation Via a $\mathrm{pH}$ stabilization method in monoethanolamine-based solutions for postcombustion $\mathrm{CO}_{2}$ capture. Corros. Sci. 106, 281-292 (2016).

21. Zlotnikov, l. et al. In situ elastic modulus measurements of ultrathin protein-rich organic layers in biosilica: towards deeper understanding of superior resistance to fracture of biocomposites. RSC Adv. 3, 5798-5802 (2013).

22. Gilow, C., Zolotoyabko, E., Paris, O., Fratzl, P. \& Aichmayer, B. Nanostructure of biogenic calcite crystals: a view by small-angle X-ray scattering. Cryst. Growth \& Des. 11, 2054-2058 (2011).

23. Zhang, D., Liu, Y., Shi, Y. \& Huang, G. Effect of polyhedral oligomeric silsesquioxane (POSS) on crystallization behaviors of POSS/polydimethylsiloxane rubber nanocomposites. RSC Adv. 4, 6275-6283 (2014).

24. Sanchez, C., Julian, B., Belleville, P. \& Popall, M. Applications of Hybrid OrganicInorganic Nanocomposites. J. Mater. Chem. 15, 3559-3592 (2005).

25. Tanupabrungsun, T. Thermodynamics and kinetics of carbon dioxide corrosion of mild steel at elevated temperatures doctor of philosophy thesis. Ohio University (2013).

26. Nordsveen, M., Nyborg, S. N. R. \& Stangeland, A. A mechanistic model for carbon dioxide corrosion of mild steel in the presence of protective iron carbonate films part 1: theory and verification. Corrosion 59, 443-456 (2003).

27. Liu, L., Tian, M., Zhang, W., Zhang, L. \& Mark, J. E. Crystallization and morphology study of polyhedral oligomeric silsesquioxane poss/polysiloxane elastomer composites prepared by melt blending. Polymer 48, 3201-3212 (2007).

28. Zhang, Y., Pang, X., Qu, S., Li, X. \& Gao, K. The relationship between fracture toughness of $\mathrm{CO}_{2}$ corrosion scale and corrosion rate of $\mathrm{X} 65$ pipeline steel under supercritical $\mathrm{CO}_{2}$ condition. Int. J. Greenh. Gas. Control 5, 1643-1650 (2011).
29. Gao, K. et al. Mechanical properties of $\mathrm{CO}_{2}$ corrosion product scales and their relationship to corrosion rates. Corros. Sci. 50, 2796-2803 (2008).

30. Yilmaz, S., Kodal, M., Yilmaz, T. \& Ozkoc, G. Fracture toughness analysis of O-POSS/ PLA composites assessed by essential work of fracture method. Compos. Part B: Eng. 56, 527-535 (2014).

31. Divakar, M., Agarwal, V. K. \& Singh, S. N. Effect of the material surface hardness on the erosion of AISI316. Wear 259, 110-117 (2005).

32. McCusker, C., Carroll, J. B. \& Rotello, V. M. Cationic polyhedral oligomeric silsesquioxane (POSS) units as carriers for drug delivery processes. Chemical Communications, 996-998, doi:10.1039/b416266h (2005).

33. Foss, M., Gulbrandsen, E. \& Sjoeblom, J. Adsorption of corrosion inhibitors onto iron carbonate $\mathrm{FeCO}_{3}$ studied by zeta potential measurements. J. Dispers. Sci. Technol. 31, 200-208 (2010).

34. Philippini, V., Naveau, A., Catalette, H. \& Leclercq, S. Sorption of silicon on magnetite and other corrosion products of iron. J. Nucl. Mater. 348, 60-69 (2006).

35. Zhang, Z., Liang, G. \& Wang, X. Epoxy-functionalized polyhedral oligomeric silsesquioxane/cyanate ester resin organic-inorganic hybrids with enhanced mechanical and thermal properties. Polym. Int. 63, 552-559 (2014).

36. Jiao, J., Wang, L., Lv, P., Cui, Y. \& Miao, J. Improved dielectric and mechanical properties of silica/epoxy resin nanocomposites prepared with a novel organic-inorganic hybrid mesoporous silica: POSS-MPS. Mater. Lett. 129, 16-19 (2014).

37. Wang, J. Q., Atrens, A., Cousens, D. R. \& Kinaev, N. Microstructure of X52 and X65 pipeline steels. J. Mater. Sci. 34, 1721-1728 (1999).

38. Burkle, D. et al. Development of an electrochemically integrated SR-GIXRD flow cell to study $\mathrm{FeCO}_{3}$ formation kinetics. Rev. Sci. Instrum. 87, 105125 (2016).

39. Singh, D. D. N. \& Kumar, A. A fresh look at ASTM G 1-90 solution recommended for cleaning of corrosion products formed on iron and steels. Corrosion 59, 1029-1036 (2003).

40. Oliver, W. C. \& Pharr, G. M. An improved technique for determining hardness and elastic modulus using load and displacement sensing indentation experiments. J. Mater. Res. 7, 1564-1583 (1992).

(i) Open Access This article is licensed under a Creative Commons Attribution 4.0 International License, which permits use, sharing, adaptation, distribution and reproduction in any medium or format, as long as you give appropriate credit to the original author(s) and the source, provide a link to the Creative Commons license, and indicate if changes were made. The images or other third party material in this article are included in the article's Creative Commons license, unless indicated otherwise in a credit line to the material. If material is not included in the article's Creative Commons license and your intended use is not permitted by statutory regulation or exceeds the permitted use, you will need to obtain permission directly from the copyright holder. To view a copy of this license, visit http://creativecommons. org/licenses/by/4.0/.

(c) The Author(s) 2017 